Parte III 



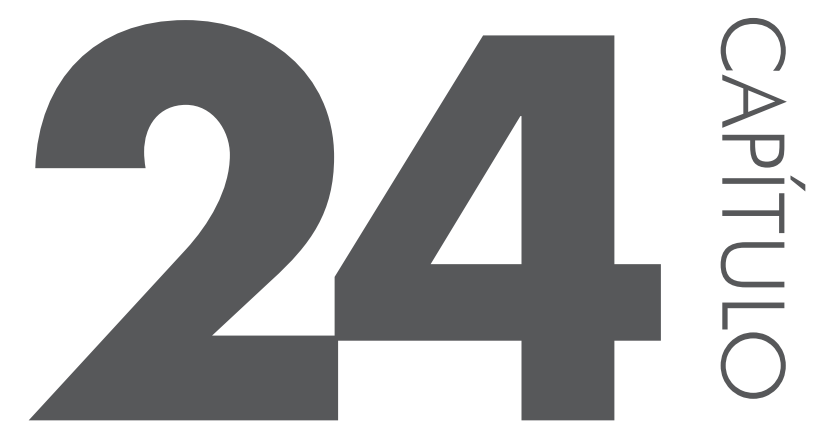

\section{A CONGADA E O MITO DO ACHAMENTO DA SANTA DO ROSÁRIO: PRIMEIROS ESTUDOS'}

Cássio Ribeiro Manoel ${ }^{2}$ Maria Helena de Paula ${ }^{3}$

Resumo: Sabendo-se que o léxico é o tesouro cultural de uma dada comunidade, no qual se visualizam diferentes momentos de sua história cultural e social, o presente trabalho propõe um estudo do mito do achamento da Santa do Rosário, embasado nos esboços acerca do mito fundador proposto por Chauí (2007),

1 Este texto é uma versão com discussões mais elaboradas do resumo expandido de título homônimo, publicado nos Anais do I Conpeex da UFG/Regional Catalão, realizado em junho de 2015, em Catalão-GO.

2 Universidade Federal de Goiás/Regional Catalão, Catalão-GO, Brasil, FAPEG

3 Universidade Federal de Goiás/Regional Catalão, Catalão-GO, Brasil, FAPEG

E-mail de contato: cassim.ribeiro2@hotmail.com; mhp.ufgcatalao@gmail.com 
constituído por palavras. Para tanto, esta pesquisa é desenvolvida mediante histórias contadas por dançadores da Congada de Catalão-GO, a partir de cantigas que regem as festividades em Louvor a Nossa Senhora do Rosário. Ademais, esta investigação, caracterizada pela pesquisa bibliográfica, apresenta os relatos sobre o mito do achamento, baseados nos estudos de Brandão (1985), e fazem alusão à história da Congada de Catalão, mais especificadamente à história de um dos ternos mais expressivos dentro da Congada, o "Moçambique Mamãe do Rosário". Para isso, apresentamos uma cantiga que evidencia a questão do mito, inventariando algumas unidades lexicais por meio do expediente lexicográfico, para demonstrar brevemente a historicidade do referido mito. Para atender nosso intento, nos embasaremos em estudos lexicográficos, como de Biderman (2001) e Coelho (2008), dentre outros.

Palavras-Chave: Congada; Mito; Vocabulário.

Abstract: Because the lexicon is the cultural treasure of a certain community, in which the different moments of the cultural and social history of a society are visualized, this paper proposes a study of the myth of the achamento of the Saint of Rosary, grounded on the sketches about the founding myth, constituted by words, proposed by Chauí (2007). To this, this research is developed from histories told by dancers of the Congada of Catalão-GO, songs that lead the festivities in laudation of Our Lady of the Rosary. Furthermore, this investigation, characterized by bibliographical research, presents the reports about the myth of the achamento, grounded on the studies by Brandão (1985) and that allude to the history of the Congada of Catalão, more specifically the history of one of the more expressive ternos inside the Congada, which is "Moçambique Mamãe do Rosário". Thereunto, we tried to bring a song that shows the matter of the myth, inventorying some lexical units through the expedient lexicographic vocabulary, which briefly shows the historicity of the referred myth. For our aim, We will count on the help of the lexicographic studies of Biderman (2001) and Coelho (2008), among others.

Keywords: Congada; Myth; Vocabulary.

\section{INTRODUĈ̣̃O}

Este trabalho apresenta os resultados parciais da pesquisa acerca do mito do achamento da Santa do Rosário, que rege toda a festividade em Louvor a Nossa Senhora do Rosário na cidade de Catalão-GO, sendo que a real motivação para a presente pesquisa é a participação dos pesquisadores no âmbito da Congada desde a infância. A Congada de Catalão é uma manifestação religiosa e, ao mesmo 
tempo, cultural, sendo uma forma de os dançadores dos ternos ${ }^{4}$ que compõem a Congada prestarem seus louvores à Santa do Rosário por meio de suas cantigas e performances diversas, como danças, cortejos e representações dramáticas e religiosas. A Congada é a manifestação cultural que simboliza a persistência e a resistência da cultura negra numa sociedade constituída, na maioria das vezes, por brancos que acabam banalizando as relações desses grupos sociais, mesmo que a identidade negra esteja majoritariamente presente na festa e seja a sua principal motivação. Vale ressaltar que a Congada de Catalão acaba sofrendo com esse tipo de preconceito étnico, pois a festa em si é regida por brancos e o negro só tem o papel de dançar, repetindo suas performances de lutas historicamente presentes na constituição de tal manifestação cultural.

Essa manifestação, com acontecimento sazonal na cidade há ininterruptos 139 anos, tem origem africana, constituindo-se como uma festa em que os aspectos culturais e religiosos da população vêm à tona. Reconhece-se nessa festa uma manifestação de cultura popular que acontece na cidade, fazendo parte do cotidiano dos participantes. Machado (2002), em seu estudo acerca da cultura popular, nos faz compreender a cultura como forma de sentir as práticas do nosso dia a dia, pois,

a cultura é um modo específico de ver, sentir e representar o mundo em que se vive; para estudar as suas formas de representações culturais é preciso, antes de qualquer coisa, penetrar pelo interior de uma determinada realidade social, desvendar a lógica de como essas representações foram construídas e apresentadas ao público, o que pode estar presente nos gestos, na linguagem, nas práticas cotidianas de trabalho, lazer e religiosidade (MACHADO, 2002, p. 336).

Antes de nos remeter à Congada de Catalão, buscaremos compreender o surgimento dessa prática cultural. O ritmo da Congada surgiu na África, quando o reino do Congo passou a ser destruído por Portugal, vindo a representar a luta do negro pela liberdade, pois o título do Rei do Congo era de extrema importância e valor. No Brasil, o ritmo surgiu mais especificamente em Recife, um dos lugares onde desembarcavam os negros que vinham da África e um dos primeiros lugares onde houve a repetição do ritual da luta do negro contra o branco, em alusão ao ritual que era feito na África, representado por danças como a capoeira; daí teriam surgido as Congadas em vários lugares do nosso país, enfatizando a luta pela liberdade (RIBEIRO, 2014). O início dessa festividade na cidade de Catalão deu-se em meados de 1820, e não se sabe ao certo quando se iniciaram as homenagens à santa. No entanto, é notório que escravos semilibertos chegaram

4 Terno, nesse caso, são grupos de pessoas, homens e mulheres, crianças, jovens e adultos que dançam para louvar Nossa Senhora do Rosário. 
na cidade quando esta ainda tinha o nome de Vila do Catalão. Eles vieram para trabalhar nas lavouras e trouxeram consigo suas crenças e costumes.

Com o passar dos anos, essas manifestações africanas passaram a se misturar com os ritos do catolicismo, formando o que chamamos hoje de sincretismo religioso, em que os participantes dessa festa louvam a Santa do Rosário e os seus orixás, entidades cultuadas nas religiões de matizes africanas, como a Umbanda e o Candomblé, sendo possível, por meio de algumas cantigas, ouvir cantorias que apresentam mensagens que reelaboram o momento da trajetória do negro da África para o Brasil ou até mesmo da importância da inserção da cultura, da crença e dos costumes africanos na cultura brasileira.

São várias as versões do início das festividades em Catalão. Robson Macedo (2007), mediante o estudo de jornais e entrevistas com (e de) participantes mais velhos, defende que a origem dos festejos se deu com um fazendeiro que migrou de Minas Gerais para a cidade por volta da década de 1860. Com medo da nova fase que se iniciava na cidade, prometeu à virgem que, se fosse bem-sucedido, como pagamento realizaria uma grandiosa festa em sua homenagem. Tudo deu certo em sua nova vida e, anos mais tarde, quando previa sua morte, passou a responsabilidade ao seu filho. Este se casou, mas, quando pretendia realizar a festa, o vigário da cidade não aceitou a homenagem à santa, alegando ser uma festa pagã, trancando a igreja e levando consigo as chaves. Isso não impediu que a festa acontecesse, pois a população arrombou a porta do templo e realizou a homenagem à Nossa Senhora do Rosário como tem feito até os dias de hoje.

Ritmos, danças, batuques e apitos anunciam na cidade algo determinante para a sua identidade cultural: a fé em Nossa Senhora do Rosário. A Congada de Catalão se perpetua há mais de um século, fazendo com que novos e velhos congadeiros saiam às ruas para expressar seus louvores à santa. O início da Congada foi uma conquista dos negros e afrodescendentes, que puderam celebrar sua fé longe dos cativeiros, fazendo com que os caminhos trilhados, movidos pela fé de um povo, passassem a expressar e a construir o sentido da vida, dos mistérios e da força que movem essa população devota.

A festa do Rosário, para muitos moradores de Catalão, é a forma de rompimento momentâneo com o cotidiano, pois o festejar muda a rotina da cidade, fazendo com que toda a população participante dessa manifestação cultural se prepare para vivenciar todos os momentos da festa, antes, durante e depois da celebração, quando a rotina da cidade volta ao normal, ainda que no "calendário religioso" da festa, os dez primeiros dias sejam o seu marco principal.

O ponto crucial deste estudo é a busca pelo conhecimento do mito que funda toda a festividade em Louvor à Senhora do Rosário. Para isso, recorre-se a Chauí (2007), que discute a importância do mito fundador, como o que exprime 
linguagens que parecem ser novas, mas são repetições. Nesse sentido, tem-se o mito do achamento da Santa do Rosário que, durante as festividades em Catalão, é repetido nos rituais e os rege, uma vez que é por meio dele que a Congada vem se perpetuando até os dias de hoje. Dentre as várias versões contadas por dançadores, capitães, presidente da Irmandade, dentre outras pessoas mais velhas no âmbito da Congada, é que será tecida a concepção do mito dessa festividade usada nesta pesquisa.

Nesse contexto, Campos (1940 apud CHAUÍ, 2007, p. 57) afirma que “criamos nosso mito. O mito é uma crença, uma paixão. Não é necessário que seja uma realidade. É realidade efetiva, porque estímulo, esperança, fé, ânimo. Nosso mito é a nação; nossa fé, a grandeza da nação". No entanto, o mito se torna real, pois é aquilo que faz com que devotos e participantes da festa busquem cada vez mais viver a sua fé na Santa do Rosário, perpetuando essa manifestação cultural e religiosa.

Sabe-se que o mito é passado oralmente, de geração a geração, e que, supostamente, foi passado entre os negros escravos, tanto na África quanto no Brasil. Entre os dançadores da Congada, as razões de sua dança são religiosas, pois, para os poucos que conhecem o mito, é assim que conservam a sua crença, tradição e fé na Santa do Rosário (BRANDÃO, 1985). É por meio do mito que pessoas da Congada, em especial as mais velhas, mediante suas memórias, remetem outros congadeiros e estudiosos ao surgimento e ao como deve(ria) ser o regimento de toda a festividade, no cenário constante de mudanças próprias da cultura popular, especialmente a que enfrenta dinâmicas de espetacularização junto às culturas de massas que, com essa manifestação religiosa e cultural, convive e se relaciona.

O intuito deste estudo é apresentar resultados dos primeiros estudos da pesquisa de mestrado intitulada Relações linguístico-históricas no mito do achamento da santa do Rosário: um estudo do "Moçambique Mamãe do Rosário" de Catalão-Goiás”, para o que são conclamados os estudos lexicais, com o fito de se construir um breve vocabulário. Considera-se, para este fim, que o léxico é o patrimônio vocabular de uma comunidade linguística ao longo da história, registrando e acumulando as representações dessa comunidade, uma vez que "o léxico tem sido relacionado com a memória humana” (ZAVAGLIA, 2012, p. 232), de modo que inventariar, descrever e discutir o léxico da Congada de Catalão é, então, uma maneira de conhecer o mito que a rege e, em certa medida, a memória que a constitui. Para isso, o material de estudo será uma cantiga executada pelo terno Moçambique Mamãe do Rosário que, na história da Congada, foi quem conseguiu retirar a santa do deserto e trazê-la ao âmbito do sagrado, isto é, a igreja.

Tendo em vista que o mito sustenta a festa em questão por mais de um século, é válido lembrar que, para Chauí (2007, p. 9), “um mito fundador é aquele que não cessa de encontrar novos meios para exprimir-se, novas linguagens, novos valores e ideias, de tal modo que, quanto mais parece ser outra coisa, tanto mais 
é a repetição de si mesmo". No enlaço das palavras da autora, nos dias principais do festejo (segundo final de semana da primeira quinzena do mês de outubro), o ritual é reafirmado, pois o Moçambique e os demais ternos que constituem a Congada vão até à igreja, o espaço do sagrado, onde estão a imagem de Nossa Senhora do Rosário e a Coroa, símbolos venerados nos rituais da festa, e os levam mediante cortejo para a rua, então espaço do profano, constituída, a partir dos rituais, como o espaço misto, sincrético, do festejo.

Com o andamento da pesquisa de mestrado supracitada, haverá de se demonstrar se o mito do achamento, contado nas memórias orais dos dançadores mais velhos, comporta ou não a historicidade dessa festa, sendo refeito todos os anos o ritual de retirada da santa dos locais sagrados para a rua. As proposições de discussão e diálogos teóricos do presente estudo, como Halbwachs (2006, p. 80), consideram que "é na memória histórica que temos que nos basear", e é nessas memórias que se perseguirá o sentido dessa manifestação de cultura popular, tendo como base especificamente as várias linguagens que se circunscrevem ao terno Moçambique.

\section{MOÇAMBIQUE E O MITO}

A Congada de Catalão é composta por 21 ternos de Congo, como Catupé, Congo, Vilão, Marinheiro, Marujeiro, Penacho e Moçambique, que trazem o colorido e dão sentido à festa de Nossa Senhora do Rosário. Entre eles, tem-se diferentes ritmos, vestimentas e performances, todos com sua importância nos diferentes rituais, uma vez que, em cada terno dançam homens e mulheres que cantam seus louvores à Santa Padroeira. Dentre todos esses ternos, o mais importante na abertura, na permanência e no encerramento dos rituais é o Moçambique, pois ele é o guardião dos mistérios e da Coroa, e aquele que conduz esses símbolos durante a Festa. Nesse sentido, os batuques das caixas, e os pulos e gingados da dança fazem com que os dançadores se tornem fortes e persistentes, pois, por meio da sua devoção, eles conseguem restabelecer-se diante dos conflitos do dia a dia, e seus repetidos gestos fazem com que se mantenham vivas suas memórias, para agregarem em si a força e a proteção da Santa do Rosário.

O Moçambique é o menor terno que compõe a Congada, com média de cinquenta a cem dançadores nos dias atuais - antigamente não havia mais que vinte dançadores. Historicamente, o Moçambique é o guardião da imagem de Nossa Senhora do Rosário e a acompanha em todos os rituais do festejo. Esse compromisso advém desde os primórdios do achamento da santa, sendo por muitos considerada a festa de Maria desde o princípio do mundo, afinal, como diz a lenda, foi o Moçambique quem a retirou do rochedo.

Vale ressaltar que na festa do Rosário de Catalão há dois Moçambiques, o Mamãe do Rosário e o Coração de Maria. O foco deste estudo é o Moçambique 
Mamãe do Rosário ${ }^{5}$, que tem o dever de conduzir a imagem de Nossa Senhora para os momentos religiosos da festa, sendo considerado como a presença do sagrado em meio aos devotos. Já o Moçambique Coração de Maria é o que conduz a Coroa e o Reinado, tendo ele, dentro do festejo, um importante papel, pois a Coroa é o segundo símbolo de veneração e fé na festa.

Várias são as versões de como foi encontrada e retirada a santa do deserto. No entanto, a versão mais pertinente nos festejos de Nossa Senhora do Rosário de Catalão, e aquela seguida por dançadores e capitães, é a versão repassada como memória oral do grupo e de admiradores, proposta pelos estudos do antropólogo Carlos Rodrigues Brandão:

\begin{abstract}
Uma santa apareceu na rocha, algumas pessoas conseguiam vê-la e outras não, o padre celebrava missa no local, levava grupo musical com o intuito de conduzir a santa para uma igreja, ela os acompanhava, mas no outro dia voltava para o rochedo. Foram várias tentativas da parte da igreja e da população, mas foi "Pai João" que visitou a santa e a reconheceu como mãe (mãe dos pretos), dali por diante ele arrebanhou um grupo de pessoas com alguns instrumentos retirados da mata, reproduziram um ritual próprio em frente à santa, conseguiram retirá-la e colocaram-na numa igreja, onde permanece até hoje (BRANDÃO, 1985, p. 84).
\end{abstract}

Esta é versão mais pertinente e aquela que comumente se repete entre os dançadores. Contudo, não se pode esquecer que a festa do Rosário de Catalão é oriunda do estado de Minas Gerais, no qual a festa tem um forte envolvimento com as práticas dos cultos africanos (Umbanda e Candomblé), cultuando-se não apenas a Nossa Senhora do Rosário, mas também os orixás, constituindo o sincretismo religioso. Ressalta-se que a Senhora do Rosário, na historicidade da Congada mineira, foi encontrada nas águas e não no deserto, fazendo alusão à Mãe das Águas, Iemanjá. Ainda que a festa de Catalão tenha sido oriunda de Minas, há uma diferença significativa entre elas na dança, na vestimenta, nas cantigas e performances, inclusive nas memórias que circunscrevem o mito do achamento da santa, o que concede diferentes formas de revivê-la e expressa diferentes sentidos de louvar a padroeira dos negros.

O Moçambique, na festa de Nossa Senhora do Rosário de Catalão, é de extremos importância e valor. Uma Festa do Rosário em Catalão sem o Moçambique não existe, pois, como forma de reafirmar o mito, é ele que carrega a bandeira, a Coroa e o Reinado para as cerimônias que compõem a festa, inclusive na Entrega da Coroa. Assim, embora todos os demais ternos reconheçam-se importantes na Congada de Catalão, nenhum outro pode conduzir os símbolos da festa, a não ser o Moçambique, por ser considerado o que tem integrantes mais

5 O primeiro autor do presente estudo é dançador neste terno desde a infância. 
humildes, que são negros e os que mais conseguem eficácia diante da santa, pois, como remete Brandão (1985, p. 87),

são os Moçambique, mais pobres, mais humildes, mais mal arrumados e mais lentos do que os congos, os que conseguem uma eficácia plena diante da santa. São os negros de Pai João, sem recursos, mas “filhos da santa”, os que conseguem fazer-se acompanhar dela, depois de gastos os recursos do padre e sua gente.

O Moçambique, pela sua representatividade nos quadros ritualísticos da Congada, tende a fascinar a população com a batida peculiar dos seus tambores e demais instrumentos. As cantigas são entoadas para retratar a luta dos negros pela libertação e relembrar como foi encontrada a Santa do Rosário, considerada a "libertadora" dos negros e confundida, em algumas cantigas, com a Princesa Isabel, responsável por abolir a escravatura.

Com o intuito de compreender o surgimento das festividades de Nossa Senhora do Rosário por meio do mito que rege a Congada de Catalão, serão apresentados cinco verbetes para constituir um breve vocabulário. Este estudo é regido pela compreensão de que o vocabulário tem a função de apresentar um lema e sua significação de forma sucinta, em comparação ao dicionário. Para Coelho (2008, p. 21),

o vocabulário já é mais restrito se apresenta como um conjunto de palavras de um determinado campo, ou de um autor ou de uma obra. Normalmente, a informação apresentada num vocabulário é bem mais sucinta: depois do lema em entrada não aparece a taxonomia e no final do verbete não há abonações, como só acontece nos dicionários - praticamente os verbetes possuem apenas a entrada e a explicação, às vezes, exemplificação.

Diante disso, esses verbetes têm como corpus uma cantiga que caracteriza o mito e é entoada pelo Moçambique. Essa cantiga é a forma pela qual os dançadores expressam o linguajar do seu povo. Antunes (2009, p. 19) diz que "o povo tem uma identidade, que resulta dos traços manifestados em sua cultura, a qual, por sua vez, se forja e se expressa pela mediação das linguagens, sobretudo da linguagem verbal”. Com isso, compreende-se que as cantigas são a forma pela qual a Congada expressa sua devoção à santa.

A cantiga é um gênero musical que tem a função de mostrar os louvores à Santa do Rosário, nas novenas, nas missas e em outras formas de devoção, como os louvores feitos à padroeira. Compreende-se, pois, “em Catalão, que Nossa Senhora do Rosário é uma santa branca, de uma igreja sob o controle de brancos. No entanto, é padroeira dos negros que, em seu nome, produzem uma festa" (BRANDÃO, 1985, p. 88). Essa tradição é garantida não somente por meio das cantigas, mas por outros acontecimentos dentro da festa. 


\section{VOCABULÁRIO}

Este estudo toma a Congada como manifestação de cultura popular, considerando a língua (a cantiga adiante apresentada) como expressão da cultura nas relações sociais, sendo indissociáveis a língua e a cultura. Assim, para compreender o linguajar desse grupo de congadeiros e entender os sentidos dessa manifestação cultural para a população, recorre-se a Fiorin (2003), que afirma que "não existe cultura sem língua; a língua, de certa forma, seria o que propicia a construção da cultura. Sem a língua não teríamos a cultura [...]; a língua seria, digamos, um modelo de estruturalidade para linguagens da cultura de maneira geral" (FIORIN, 2003, p. 72-73). No enlaço das palavras de Fiorin, pelas estruturas da língua podemos compreender as formas culturais de uma dada comunidade nelas representadas: no caso do estudo apresentado, trata-se de compreender a comunidade congadeira de Catalão e como se faz registrar, na sua linguagem, as memórias do mito do achamento da Santa do Rosário.

Considera-se, para o presente estudo, que a dinâmica da língua a faz paradoxal, pois ela só muda porque permanece; o seu caráter de imutabilidade dá-lhe garantias de que as mudanças por que passará não a farão se perder no tempo e lhe garante a sistematicidade e comunicabilidade. É um movimento de permanecer e avançar, porque a língua é um bem social, mormente conhecida pela cultura, mas assegurada pelas estruturas que a fazem sistema. Para Borba (2006, p. 81), “compreende-se a língua, o sistema, como fazendo parte da cultura e, ao mesmo tempo, ela é tomada como um espelho do restante dos dados culturais, cuja agudeza de imagem acarreta uma série de indagações capazes, em princípio, de resposta empírica”.

No entanto, a língua é a condição de existência da cultura; só existe para englobá-la, comunicá-la e transmiti-la, pois não haveria cultura sem uma língua que lhe servisse; é a cultura que se estrutura na língua, como o meio de demonstrar as representações culturais de uma sociedade. Em um de seus estudos, Câmara Jr. afirma que a língua é um fato de cultura como qualquer outro; integra-se na cultura e tem a função de expressá-la, pois a língua relaciona-se com os aspectos culturais (CÂMARA Jr., 2004).

A língua, como compreendida por Saussure e pela maioria dos pesquisadores, "é um sistema de signos que exprimem ideias" (SAUSSURE, 2012, p. 47), tendo ela as possibilidades combinatórias de manter vivos a gramática e o léxico. O léxico, como parte da língua nas suas múltiplas modalidades e gêneros, é o foco deste artigo: é pela compreensão do léxico nas cantigas e nas memórias orais de congadeiros que se procurará os sentidos para o surgimento dessa festa, especialmente pela compreensão do mito do achamento da santa do Rosário.

Seguindo os pressupostos da tese do mestre de Genebra, para quem “a linguagem implica ao mesmo tempo um sistema estabelecido e uma evolução, a cada 
instante, ela é uma instituição atual e produto do passado" (SAUSSURE, 2012, p. 40), compreende-se que, com o nosso intuito de abarcar os estudos lexicais por meio das cantigas e considerando o léxico o conjunto de palavras de uma língua, o seu estudo trará à tona a memória do passado vivenciada nos dias de hoje, pois “a língua é parte social da linguagem" (SAUSSURE, 2012, p. 46). A língua, no seio da sociedade, abarca os limites do pensar e do sentir, ampliando as possibilidades das relações humanas e de compreensão destas relações.

Na perspectiva de que língua e cultura são indissociáveis, Petter (2015) diz que "a linguagem é relativamente autônoma; como expressão de emoções, ideias, propósitos, no entanto, ela é orientada pela visão de mundo, pelas injunções da realidade social, histórica e cultural de seu falante" (PETTER, 2015, p. 11). Tal compreensão, aplicada ao nosso objeto de estudo, há de tomar o linguajar da Congada, especialmente as suas cantigas, como a maneira pela qual os dançadores expressam suas emoções e fazem seus propósitos diante da santa, conferindo sentido cultural, social e histórico à Festa de Nossa Senhora do Rosário.

Passando-se ao propósito de tecer as primeiras considerações acerca do léxico da comunidade congadeira, recorre-se a Coelho que, em seu estudo, diz que "o sistema de signos, correspondendo ao léxico, é o inventário das unidades significativas com as quais se representa o mundo perceptível - as palavras" (COELHO, 2008, p. 80), que podem ser faladas ou escritas. Assim, neste estudo, é a partir das memórias orais dos capitães, dançadores e participantes ativos da festa, que se buscará compreender o linguajar e a cultura dessa comunidade mediante as lexias que compõem o universo das memórias dessa população de congadeiros, especialmente ao evocarem histórias da constituição primeira das motivações da fé e dos rituais, notadamente sobre o mito do achamento da santa e relevância do terno Moçambique na tradição.

A linguagem é parte do cotidiano dos indivíduos porque, como meio de comunicação social, ela está presente nos pensamentos, nas práticas culturais e nas relações diversas que a sociedade cria e recria diuturnamente em sua constituição. Assim, cabe esclarecer que:

a linguagem pode ser definida incialmente como qualquer processo de comunicação [...]. Também pode ser compreendida como a faculdade que os homens têm de se comunicarem utilizando um sistema semiológico socialmente elaborado, existindo sob forma de memória coletiva e à disposição das pessoas de uma mesma comunidade lingüística (COELHO, 2008, p. 77).

Com o intuito de compreender o sentido do mito que rege a festa de Nossa Senhora do Rosário, passado de geração a geração por meio da memória dos integrantes mais velhos da Congada, ressalta-se que "nossa memória não se apoia na história aprendida, mas na história vivida” (HALBWACHS, 2006, p. 78), pois a 
memória materializada na linguagem, ganha existência por meio dela e é plena de significados de vida, além de a memória se alimentar da história e vice-versa. É nesse sentido que será apresentado um breve vocabulário de uma cantiga entoada pelo Moçambique Mamãe do Rosário durante o festejo. Essa cantiga é do acervo pessoal do primeiro autor deste estudo, registrada na rua durante a evolução do terno.

Ao propor um estudo lexical acerca desta cantiga, busca-se compreender como a língua, que "é um sistema de signos específicos aos membros de dada comunidade" (FIORIN, 2013, p. 14), mostra nas cantigas a forma pela qual os dançadores expressam sua devoção à santa. Diante disso, se "é o léxico que fisionomiza a cultura" (BORBA, 2006, p. 81), podemos compreender, então, que o léxico das cantigas, das memórias orais sobre a Congada é, também, um patrimônio dessa manifestação de cultura popular.

Para a composição de um vocabulário, é notório lembrar a importância do léxico entre os principais constituintes do sistema linguístico. Coelho (2008) considera as lexias mediante um ato de fala do sujeito, como a representação da língua em uso efetivo nas interações, nos mais variados e múltiplos contextos socioculturais. Nesse sentido, far-se-á uma apresentação de lexias em uma das várias cantigas que compõem o repertório do Moçambique Mamãe do Rosário, mediante o expediente do vocabulário, no intuito de demonstrar a historicidade do mito que rege toda a festa.

Assim, como coloca Biderman,

qualquer sistema léxico é a somatória de toda experiência acumulada de uma sociedade e do acervo da sua cultura através das idades [...], embora o léxico seja patrimônio da comunidade linguística, na prática, são os usuários da língua - os falantes - aqueles que criam e conservam o vocabulário dessa língua (BIDERMAN, 2001, p. 179).

Para representar o léxico do grupo que compõe a Congada como um dos seus tesouros culturais, buscou-se nos relatos dos integrantes mais velhos da Congada a repetição sobre os rituais feitos durante a festa, relativos ao mito do achamento da Santa do Rosário; também, para estudar os vocábulos dessa cantiga com o intuito de demonstrar traços do mito, pois não se pode prescindir da construção de um diálogo social e cultural como essência para louvar e reforçar a fé na santa. De acordo com Borba (2006, p. 82), o léxico é entendido como o conjunto das palavras lexicais que fisionomiza a cultura porque a representa, fixa e transmite, o intuito deste estudo lexical é compreender e, na medida possível, permitir que outros compreendam a historicidade do mito do achamento.

Levando em consideração a diversidade vocabular desta manifestação cultural, Zavaglia, em um dos seus estudos, diz que "o léxico é enraizado aos costumes, às tradições, à moral de uma determinada cultura e de seus habitantes; ele 
expressa uma visão de mundo particular de uma língua específica" (ZAVAGLIA, 2012, p. 232), e este estudo se recobre de salutar importância por buscar compreender, por meio do estudo lexicográfico, como esta comunidade de congadeiros mostra seus costumes, sua dança e sua devoção na Santa do Rosário.

Ainda de acordo com as concepções de Zavaglia (2012),

é o léxico, em forma de palavras e por meio da linguagem, que "conta” a história milenar de povo para povo; é o léxico que transmite os elementos culturais de um conjunto de indivíduos; é o léxico que "proíbe" manifestações ou então "incita”; é o léxico que "educa" ou "deseduca"; é o léxico que permite a manifestação dos sentimentos humanos, de suas afeições ou desagrados, via oral ou via escrita. É o léxico que registra o desencadear das ações de uma sociedade, suas mudanças, seu progresso ou regresso (ZAVAGLIA, 2012, p. 233).

É, pois, por meio das memórias orais e das cantigas da história secular deste povo congadeiro, recontada e recriada por gerações e para as gerações futuras, que se poderá compreender os muitos sentidos dos louvores referidos à Santa do Rosário na cidade de Catalão. Se as unidades lexicais do linguajar dos congadeiros é portadora de significados que deixam transparecer os momentos da história cultural desta sociedade, ratifica-se que "o léxico de uma língua natural constitui uma forma de registrar o conhecimento do universo" (BIDERMAN, 2001, p. 13) - no caso estudado, as cantigas entoadas durante o festejo são uma forma pela qual se busca registrar o léxico usado por esta comunidade de congadeiros por ocasião de seus festejos.

Como essa tradição tem forte influência da cultura afrodescendente, o Moçambique tem, também, uma característica para manifestar sua homenagem à padroeira da cidade. Na cantiga entoada pelo Moçambique Mamãe do Rosário no momento de retirada da imagem de Nossa Senhora da igreja, e de encontro com o terno de Congo, evidenciam-se as relações histórica e mnemonicamente construídas e que têm, no Moçambique, o precursor do mito.

A título de exemplificação, segue parte da cantiga entoada pelo Moçambique Mamãe do Rosário no ano de 2014:
A Sinhora do Rosário,
foi achada no diserto,
Moçambique foi quem tirou,
mais o Congo estava perto.

Nesse sentido, com o intuito de preparar um breve vocabulário, conforme definição linguística, seguem cinco termos mencionados nessa cantiga que apontam traços do mito: 
ACHADA - adj.f. diz-se da condição da imagem santa de Senhora do Rosário, achada por dançadores do Moçambique e do Congo.

CONGO - s.m. terno que compõe a Congada, tendo como instrumentos caixas designando escravos do antigo reino do Congo.

DESERTO - s.m. lugar onde foi encontrada e retirada do rochedo a imagem de Nossa Senhora do Rosário.

MOÇAMBIQUE - s.m. menor terno da Congada, responsável por conduzir a imagem de Nossa Senhora para as ruas; designa escravo guerreiro originário do país de mesmo nome.

NOSSA SENHORA DO ROSÁRIO - s.f. santa festejada pela congada de Catalão; padroeira dos negros; aquela que tem sua imagem pintada na bandeira.

No entanto, o terno traz como vocabulário vários lemas com características do perfil cultural do grupo. Nesse sentido, há questões voltadas para o mito do achamento da Santa do Rosário, mostradas por meio da miscigenação cultural das formas ritualísticas feitas durante o festejo, e essa é a razão pela qual este estudo lexical possibilita distintas leituras desta cultura, porque corrobora variadas tendências, repaginando a historicidade dessa tradição catalana com forte influência da cultura afrodescendente.

Ao falarmos da historicidade da Congada de Catalão, é importante salientar que, por meio da organização de um breve vocabulário, podemos evidenciar uma manifestação de herança cultural com o fim de conhecer vestígios do mito do achamento da Santa do Rosário, um patrimônio-memória a constituir o tesouro cultural abstrato da língua, ou seja, uma herança de signos lexicais que apontam parte da constituição do acervo linguístico e cultural do português usado no Brasil, em especial no contexto no qual se insere o Moçambique Mamãe do Rosário, concebido neste estudo como uma manifestação cultural e religiosa, como homenagem à Senhora do Rosário, de um percurso histórico e linguístico de africanos no Brasil.

\section{CONCLUSÃO}

A Congada de Catalão é um campo rico de estudos, e este trabalho teve por finalidade demonstrar parte da tradição dessa manifestação religiosa. Por se tratar de considerações primeiras da pesquisa em andamento, este estudo carece de maiores aprofundamentos acerca do mito do achamento da Santa do Rosário. Fica evidente que o inventário lexical com vistas a constituir um vocabulário a partir de uma pesquisa bibliográfica, na tentativa de constar a versão contada por dançadores e capitães, é considerado o mais pertinente para o estudo do mito que rege as festividades de Nossa Senhora do Rosário em Catalão. 
Acredita-se que foi alcançado o propósito de entender como a Congada se configura nos dias de hoje, com a luta para que permaneçam as formas ritualísticas dos primórdios desta festa e para que, apesar das várias modificações vivenciadas por esta manifestação cultural, ela encontre respaldo na concepção de cultura popular de cunho religioso, assentada no sincretismo afro-brasileiro, sujeito às dinâmicas sazonais e históricas que lhe são peculiares.

A festa do Rosário é o momento de ruptura do cotidiano, transformando-o e dando a ele um sentido especial, diferenciando-o de dias comuns. Todos os anos, a festa dá sentido a vidas e histórias, que buscam revivê-la para estar em dia com o sagrado.

A pesquisa, ainda em fase ainda inicial de desenvolvimento, ganhará mais fôlego com a gravação de entrevistas, pesquisa de outras cantigas do Moçambique Mamãe do Rosário e consultas aos diversos materiais impressos disponíveis no Museu da Congada. Contando com material mais abrangente, outras compreensões sobre o mito e o surgimento das festividades reforçarão a hipótese de que o vocabulário pode ser considerado uma ferramenta histórica, capaz de referenciar memórias e histórias, mitos e crenças, no eterno desejo de permanecer e avançar que matiza sobremaneira as relações humanas, especialmente aquelas inscritas na linguagem.

\section{REFERÊNCIAS}

ANTUNES, I. A língua e a identidade cultural de um povo. In: . Língua, texto e ensino: outra escola. São Paulo: Parábola, 2009. p. 19-31.

BIDERMAN, M. T. C. As ciências do léxico. In: ISQUERDO, A. N; ALVES, I. M. (Org.). As ciências do léxico: lexicologia, lexicografia e terminologia. Campo Grande: UFMS, 2001. p. 13-22.

BORBA, F. Léxico e herança social. In: MARCHEZAN, R. C.; CORTINA, A. Os fatos da linguagem, esse conjunto heteróclito. Araraquara: Unesp; São Paulo: Cultura Acadêmica, 2006. p. 81-96.

BRANDÃO, C. R. A festa do Santo de Preto. Rio de Janeiro: FUNARTE; Goiânia: UFG, 1985.

CÂMARA Jr., J. M. Língua e cultura. In: UCHÔA, C. E. F. (Org.) Dispersos de J. Mattoso Câmara Jr. Nova edição revista e ampliada. Rio de Janeiro: Lucerna, 2004. p. 287-293.

CHAUÍ, M. Mito fundador. In: Brasil: mito fundador e sociedade autoritária. 7. ed. São Paulo: Fundação Perseu Abramo, 2007. p. 5-10.

COELHO, B. J. Linguagem: lexicografia e ensino de português. Catalão: Kaio Gráfica: Editora Ltda., 2008.

FIORIN, J. L. Conversas com linguistas: virtudes e controvérsias da linguística. São Paulo: Parábola, 2003. . A linguagem humana: do mito à ciência. In: . Linguística? Que é isso? São Paulo: Contexto, 2013. p. 13-43. 
HALBWACHS, M. A memória coletiva. Tradução de Beatriz Sidou. São Paulo:

Centauro, 2006.

MACHADO, M. C. T. Cultura popular: um contínuo refazer de práticas e representações. In: PATRIOTA, R.; RAMOS, A. F. (Org.). História e cultura: espaços plurais. Uberlândia: Aspectus, 2002. p. 335-345.

PETTER, M. Linguagem, língua, linguística. In: FIORIN, J. L. (Org.). Introdução à linguística. 6. ed. São Paulo: Contexto, 2015. p. 11-24.

RIBEIRO, R. O congado e a fé na santa do Rosário. O Congado, Catalão, n. 6, p. 8-9, 2014. SAUSSURE, F. de. Curso de linguística geral. 28. ed. São Paulo: Cultrix, 2012.

ZAVAGLIA, C. Metodologia em ciências da linguagem: lexicografia. In: GONÇALVES, A. V.; GÓIS, M. L. de S. (Org.). Ciências da linguagem: o fazer científico. Campinas: Mercado de Letras, 2012. p. 231-264. 
